\title{
Aqueous Synthesis of ZnSe/ZnS-2-R-Benzothiazole Nanocrystals with White Emission
}

\author{
Ying-Fan Liu, ${ }^{1,2}$ Yan-Hui Zhang, ${ }^{1}$ Guo-Qing Wang, ${ }^{1}$ Kai-Ming Mao, ${ }^{1}$ Shao-Ming Fang, ${ }^{1,2}$ \\ Zhang-Di Li, ${ }^{1}$ and Hong-Duo Tang ${ }^{1}$ \\ ${ }^{1}$ Henan Provincial Key Laboratory of Surface and Interface Science, Zhengzhou University of Light Industry, No. 166, \\ Science Avenue, Zhengzhou 450001, China \\ ${ }^{2}$ Henan Collaborative Innovation Center of Environmental Pollution Control and Ecological Restoration, \\ Zhengzhou University of Light Industry, No. 166, Science Avenue, Zhengzhou 450001, China
}

Correspondence should be addressed to Ying-Fan Liu; yfliu@zzuli.edu.cn and Shao-Ming Fang; mingfang@zzuli.edu.cn

Received 13 April 2016; Revised 6 August 2016; Accepted 15 August 2016

Academic Editor: Raul Arenal

Copyright (C) 2016 Ying-Fan Liu et al. This is an open access article distributed under the Creative Commons Attribution License, which permits unrestricted use, distribution, and reproduction in any medium, provided the original work is properly cited.

\begin{abstract}
We prepared water-soluble white light-emitting ZnSe/ZnS-2-R-benzothiazole nanocrystals (NCs), R = 2-hydroxy-5-(2,5-dimethylthienyl)-phenyl. The penicillamine (Pen) capped ZnSe/ZnS NCs were firstly prepared with high photoluminescence quantum yields (PL QY) of 40\%. Then they bond to 2-R-benzothiazole molecules, resulting in white light-emitting ZnSe/ZnS-2-R-benzothiazole NCs with QY of $75 \%$ over a 375 to $650 \mathrm{~nm}$ range of emission, which can be applied to white light-emitting diodes. The ZnSe/ZnS2-R-benzothiazole NCs with two emission bands at around 451 and $557 \mathrm{~nm}$ were discussed and the possible mechanism of the interaction of $\mathrm{ZnSe} / \mathrm{ZnS}$ NCs with 2-R-benzothiazole was also proposed.
\end{abstract}

\section{Introduction}

The investigations on semiconductor nanocrystals (NCs) in the last two decades have opened the perspectives for the design and synthesis of new multifunctional materials. The wide interest in NCs arises from their unique optical and electrical properties, including broad absorption and narrow emission spectra, strong resistance to photobleaching, long fluorescence lifetime, and size-tunable emission [1-3]. These properties have created many applications of NCs for LEDs, lasers, barcoding, and biological and chemical sensing [4-8]. However, the band gap of most emissive semiconductors is either too high or low to easily make visible emitting NCs.

Until recently, there are mainly two methods to tune PL emission wavelength of the NCs: the first one is realized by size change of a few NCs, such as CdTe quantum dots (QDs), where PL is size-tunable from 400 to $700 \mathrm{~nm}[9,10]$. Although CdTe NCs exhibit high and size-tunable luminescence, the toxicity of cadmium will limit the use of these NCs, especially for bioapplications. Another method is used by doping technique. It is well-known that, as nontoxicity
$\mathrm{NCs}, \mathrm{ZnSe} \mathrm{NCs}$ having greater band gaps of $2.7 \mathrm{eV}$ are one of blue emitting semiconductors with $450 \mathrm{~nm}$ [11-13]. Hines and Guyot-Sionnest were the first to report the synthesis of luminescent TOP/TOPO-capped ZnSe NCs [14]. Due to the large band gap energy of ZnSe NCs, transition-metal Cu or Mn impurities are usually introduced into NCs to modulate their PL emission region to the UV-visible band, such as Mn doped ZnSe NCs with $590 \mathrm{~nm}$ and Cu doped ZnSe NCs with $500 \mathrm{~nm}$ [15-21]. Although size-tunable synthetic strategies and nucleation-doping technologies have been proved to be promising, more technologies need to be explored to further improve the PL QY, color tunability, and stability of the NCs.

How to control simultaneously with the emitting wavelength and intensity of the NCs may still be urgent. The organic molecules stabilizing the QD dispersion largely influence the colloidal properties of the NCs, such as the hydrodynamic size, charge, and PL QY. Hydrophilic thiols bind to QD surface atoms and simultaneously stabilize QD dispersions in polar solvents and are responsible for the surface-related optical properties of the QDs [22-25]. Using mercaptopropionic acid (MPA) as stabilizer, Lan et al. 
synthesized ZnSe QDs in aqueous solution, the QY of the asprepared ZnSe QDs improved from $8.1 \%$ to $44 \%$ under UV irradiation [26]. Wang et al. have reported the synthesis of MPA-capped ZnSe:Mn QDs [27]. Using MPA as stabilizer reagents, Fang et al. [28] have described the preparation of $\mathrm{ZnSe}: \mathrm{Mn} / \mathrm{ZnS}$ in aqueous media. However, the as-prepared QDs still possess weak luminescence, blocking their applications. Thus, it is still a great challenge to synthesize highly luminescent water-soluble ZnSe NCs.

In our previous works $[29,30]$, owing to outstanding thermal stability of Pen, we successfully synthesized Ag and $\mathrm{Ag}_{2} \mathrm{~S}$ NCs with good biocompatibility and low cytotoxicity by using Pen as stabilizer. In this work, using Pen as stabilizer reagents, we prepared $\mathrm{ZnSe} / \mathrm{ZnS} \mathrm{NCs}$ with QY of $40 \%$. Furthermore, the prepared NCs can be bond to organic fluorescent chromophore benzothiazole derivatives 2-hydroxy-5-(2,5-dimethyl-thienyl)-phenylbenzothiazole (2-R-benzothiazole), resulting in PL white emitting from 375 to $650 \mathrm{~nm}$ with as high as QY of 75\%. This observation creates inroads towards the development of novel white light-emitting diodes as discussed in the following.

\section{Experimental Section}

2.1. Chemicals. All materials used in this work were analytical reagents. Penicillamine (also named $\beta, \beta$-dimethylcysteine, 99\%, Pen), Se, and $\mathrm{NaBH}_{4}(96 \%)$ were obtained from Sigma, Inc. Thioacetamide (TAA) and $\mathrm{Zn}(\mathrm{Ac})_{2}$ were obtained from Shanghai Chemical Reagents Company. 2Hydroxy-5-(2,5-dimethyl-thienyl)-phenyl-benzothiazole (2R-benzothiazole) was provided by Dr. Xiao-Chun Li from Henan Normal University. High purity deionized water ( $>18.3 \mathrm{M} \Omega / \mathrm{cm}$ ) was produced by Millipore A10 Milli-Q.

2.2. Synthesis of Pen Capped ZnSe NCs. All the solutions were freshly prepared with deionized water prior to the synthesis. The synthesis of ZnSe NCs was performed according to [26] with some modification. Typically, ZnSe NCs were prepared by using the reaction between $\mathrm{Zn}^{2+}$ and NaHSe solution. Under vigorous stirring, the oxygen-free $0.08 \mathrm{mmol}$ of NaHSe solution was prepared by the reaction of $\mathrm{Se}$ and $\mathrm{NaBH}_{4}$ in aqueous solution. The concentrations of $\mathrm{Zn}^{2+}$ and the molar ratio of $\mathrm{Zn}^{2+}: \mathrm{HSe}^{-}$: Pen were set as $1.6 \mathrm{mM}$ and $1: 0.5: 2$, respectively. Under a robust flow of argon, $1.6 \mathrm{~mL}$ $(0.1 \mathrm{M}, 0.16 \mathrm{mmol})$ of $\mathrm{ZnAc}_{2}$ was dissolved in $100 \mathrm{~mL}$ of Milli$\mathrm{Q}$ water, and $47.8 \mathrm{mg}(0.32 \mathrm{mmol})$ of pure Pen was added. Dropwise addition of $0.5 \mathrm{M} \mathrm{NaOH}$ was then used to adjust the $\mathrm{pH}$ to 10.5 under vigorous stirring. The resulting mixture solution between $\mathrm{Zn}^{2+}$ and $\mathrm{NaHSe}$ was heated to $100^{\circ} \mathrm{C}$ under open-air conditions and refluxed for $1 \mathrm{~h}$. 2-Propanol was added to the as-prepared $\mathrm{ZnSe} \mathrm{NCs}$ colloid solution. ZnSe NCs were precipitated from the solution and collected by centrifugation. Finally, the obtained ZnSe NCs were dried at room temperature in vacuum overnight.

2.3. Synthesis of ZnSe/ZnS Nanocrystals. $70.0 \mathrm{~mL}$ of the asprepared ZnSe core NCs solution was placed in a $100 \mathrm{~mL}$ three-necked bottle. $25.1 \mathrm{mg}(0.17 \mathrm{mmol})$ of D-penicillamine,
$0.84 \mathrm{~mL}$ of $\mathrm{Zn}(\mathrm{OAc})_{2}$ solution $(0.1 \mathrm{M})$, and $0.84 \mathrm{~mL}$ of thiourea $(0.1 \mathrm{M})$ were added to $\mathrm{ZnSe} \mathrm{NCs}$ aqueous solution. Then the solution was heated to $100^{\circ} \mathrm{C}$ under open-air conditions and refluxed from $1 \mathrm{~h}$ to $50 \mathrm{~h}$. 2-Propanol was added to the as-prepared $\mathrm{ZnSe} / \mathrm{ZnS}$ NCs colloid solution. $\mathrm{ZnSe} / \mathrm{ZnS} \mathrm{NCs}$ were precipitated from the solution and collected by centrifugation. Finally, the obtained $\mathrm{ZnSe} / \mathrm{ZnS}$ NCs were dried at room temperature in vacuum overnight.

2.4. Synthesis of ZnSe/ZnS-2-R-Benzothiazole Nanocrystals. The $\mathrm{ZnSe} / \mathrm{ZnS}$ NCs precipitation was dissolved in PBS buffer solution ( $\mathrm{pH}=7.4$ ) to produce $\mathrm{ZnSe} / \mathrm{ZnS}$ PBS buffer solution. To obtain ZnSe/ZnS-2-R-benzothiazole NCs, $0.1 \sim 0.8 \mathrm{~mL}$ of the ethylene glycol solution of 2-hydroxy-5-(2,5-dimethylthienyl)-phenyl-benzothiazole (2-R-benzothiazole) was injected into $2 \mathrm{~mL}$ of freshly prepared $\mathrm{ZnSe} / \mathrm{ZnS}$ PBS buffer solution. The concentrations of $\mathrm{ZnSe} / \mathrm{ZnS} \mathrm{NCs}$ and 2R-benzothiazole were $1 \times 10^{-6} \mathrm{~mol} \cdot \mathrm{L}^{-1}$ and $5 \times 10^{-5} \mathrm{~mol} \cdot \mathrm{L}^{-1}$, respectively. 2-Propanol was added to the as-prepared $\mathrm{ZnSe} / \mathrm{ZnS}-2-\mathrm{R}-$ benzothiazole NCs colloid solution. ZnSe/ ZnS-2-R-benzothiazole NCs were precipitated from the solution and collected by centrifugation. Finally, the obtained ZnSe/Zn-2-R-benzothiazole NCs were dried at room temperature in vacuum overnight.

2.5. Characterization. UV-vis absorption and photoluminescence $(\mathrm{PL})$ spectra were measured at room temperature with a Shimadzu UV-3600 spectrophotometer and a Hitachi 7000 fluorescence spectrometer, respectively. Time-resolved luminescence measurements were carried out on an Edinburgh FLS 980 spectrofluorometer with LED lamp as light source. The excitation wavelength was $360 \mathrm{~nm}$. Ludox was applied for PL lifetime measurement in order to eliminate the influence of light scattering (i.e., excitation and emission). For all structural characterization, $\mathrm{ZnSe}(\mathrm{A})$ and $\mathrm{ZnSe} / \mathrm{ZnS}$ (B) samples were obtained after heating for 1 and $4 \mathrm{~h}$, respectively. Powder XRD measurements were taken on a Philips X'Pert PRO $\mathrm{X}$-ray diffractometer. High-resolution transmission electron microscopy (HRTEM) was performed on a Philips FEI Tecnai $\mathrm{G}^{2} 20$ S-TWIN.

\section{Results and Discussion}

3.1. XRD, TEM, and XPS Characterization. The powder XRD patterns for the $\mathrm{ZnSe}$ and $\mathrm{ZnSe} / \mathrm{ZnS}$-2-R-benzothiazole NCs (2-R-benzothiazole = 2-hydroxy-5-(2,5-dimethyl-thienyl)phenyl-benzothiazole) are depicted in Figure 1. The XRD patterns were obtained from $\mathrm{ZnSe}$ and $\mathrm{ZnSe} / \mathrm{ZnS}-2-\mathrm{R}-$ benzothiazole powders, which were precipitated from aqueous solution with an excess of 2-propanol and the precipitate was isolated by centrifugation and dried at vacuum. The characteristic zinc blend planes of 111, 220, and 311 locating at $24.04^{\circ}, 45.33^{\circ}$, and $53.80^{\circ}$ for $\mathrm{ZnSe}$ and at $27.80^{\circ}, 46.23^{\circ}$, and $54.55^{\circ}$ for $\mathrm{ZnSe} / \mathrm{ZnS}-2-\mathrm{R}-$ benzothiazole in the $2 \theta$ range of 10 to $60^{\circ}$ have been observed. The position of the XRD peaks of $\mathrm{ZnSe}$ cores matched well with those of bulk $\mathrm{ZnSe}$ cubic structure (JCPDS no. 37-1463). After growth of $\mathrm{ZnS}$ shell on $\mathrm{ZnSe}$ core, peak position shifted to higher angles towards the 


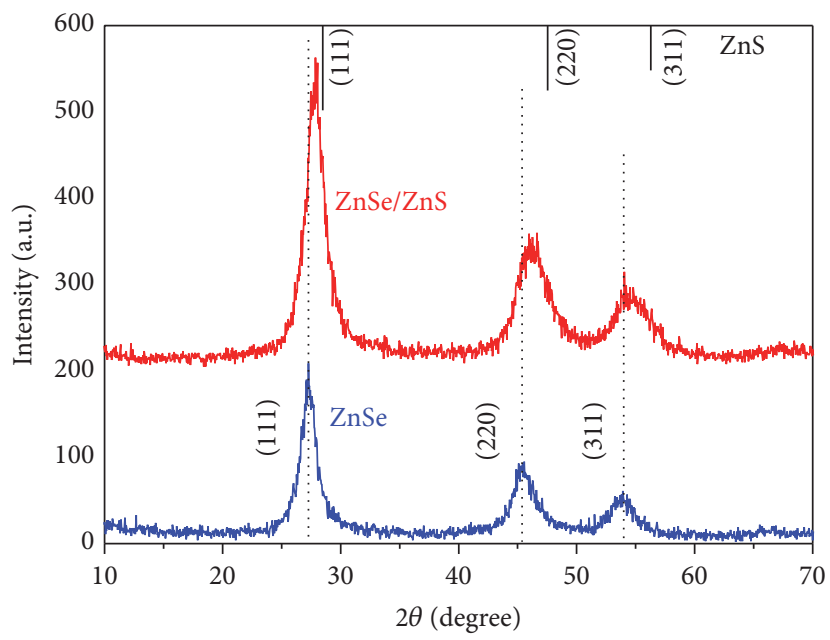

FIGURE 1: XRD patterns of ZnSe and ZnSe/ZnS-2-R-benzothiazole NCs.

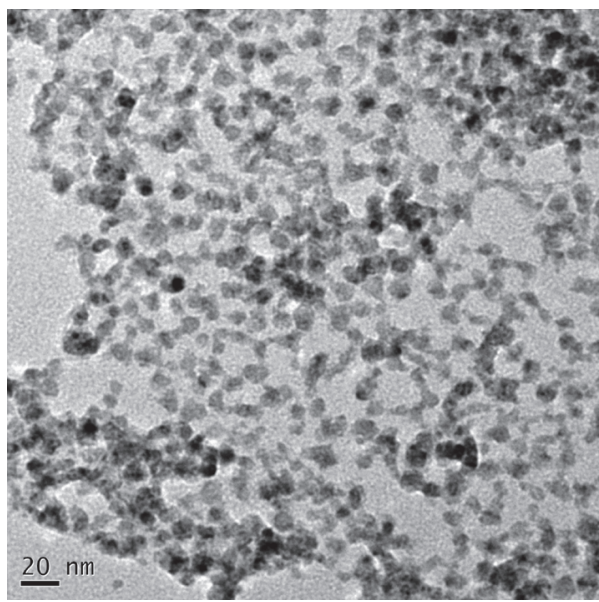

(a) $\mathrm{ZnSe}(30 \mathrm{~min})$

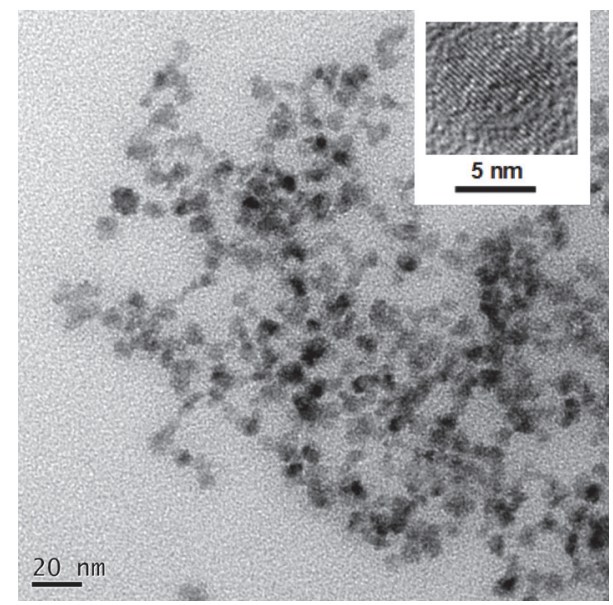

(b) ZnSe/ZnS-2-R-benzothiazole

Figure 2: TEM images of ZnSe and ZnSe/ZnS-2-R-benzothiazole NCs. The scales bars are $20 \mathrm{~nm}$ in (a) and (b). Inset: HRTEM image with a scale bar of $5 \mathrm{~nm}$.

positions of bulk ZnS cubic structure peaks (JCPDS no. 050566), which proved the formation of $\mathrm{ZnSe} / \mathrm{ZnS} \mathrm{NCs}$ and agreed with the values reported in the literature [31].

Figure 2 shows TEM images of $\mathrm{ZnSe}$ and $\mathrm{ZnSe} / \mathrm{ZnS}-$ 2-R-benzothiazole NCs. As can be seen, the as-prepared NCs are quasispheres with average size of $5.0 \pm 0.3 \mathrm{~nm}$ and $6.0 \pm 0.3 \mathrm{~nm}$, respectively, when $200 \mathrm{NCs}$ were counted. The size increase of the NCs is $1 \mathrm{~nm}$, which is mainly caused by the formation of $\mathrm{ZnS}$ layers outside the NCs. From the EDS results in Figure 3, it can be seen that $\mathrm{Zn}$, Se, and $\mathrm{S}$ are uniformly distributed in the $\mathrm{ZnSe}$ and $\mathrm{ZnSe} / \mathrm{ZnS}-2-\mathrm{R}-$ benzothiazole NCs. The S/Zn and Se/Zn of the NCs before and after core-shell formation increased from 0.14 to 0.18 and decreased from 0.43 to 0.36 . A full survey scan and $\mathrm{Zn}$, Se, $\mathrm{S}$ photoelectron spectra of the ZnSe NCs, and ZnSe/ZnS-2R-benzothiazole NCs are displayed in Figure 4. Besides the $\mathrm{Zn} 2 \mathrm{p}$ core levels, the spectra are dominated by the C1s and O1s signals stemming from the capping reagent. XPS spectra of ZnSe NCs in Figure 4 show that Zn2p, Se3d, and S 2p are 1021.40 and 1044.61; 53.50, 63.17; and $159.73 \mathrm{eV}$, respectively, while the binding energies of $\mathrm{Zn} 2 \mathrm{p}, \mathrm{Se} 3 \mathrm{~d}$, and $\mathrm{S} 2 \mathrm{p}$ for ZnSe/ZnS-2-R-benzothiazole NCs are 1021.74 and 1044.88; 53.65, 63.37; and $161.25 \mathrm{eV}$, respectively. Compared with $\mathrm{ZnSe}$ core, there is lower content of Se on $\mathrm{ZnSe} / \mathrm{ZnS}$ surface. The peak at $161.25 \mathrm{eV}$ is mainly attributed to $\mathrm{S}^{2-}$ in the $\mathrm{ZnS}$ shell [32]. The intensity of S2p binding energy $(161.25 \mathrm{eV})$ increased after $\mathrm{ZnS}$ formation on the ZnSe NCs surface. These data of $\mathrm{X}$-ray photoelectron spectroscopy (XPS) provide the direct evidence of the formation of $\mathrm{ZnSe} / \mathrm{ZnS} \mathrm{NCs}$.

3.2. Optical Properties. As found in the original reports by Fang et al. [31] and Zheng et al. [33], because superior ligand glutathione was used in the synthesis of $\mathrm{ZnSe}$ and $\mathrm{ZnSe} / \mathrm{ZnS}$ NCs, the resulting ZnSe and ZnSe/ZnS QDs possessed high PL QY up to $20 \%$ and $60 \%$, respectively. The PL of the watersoluble ZnSe NCs capped with other thiols ligands such as 


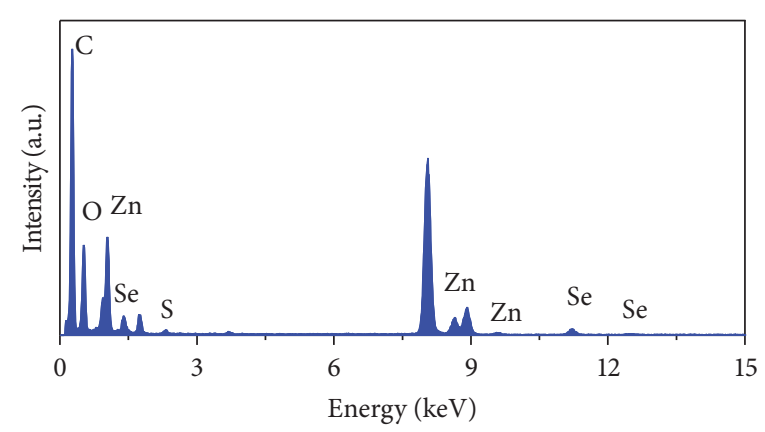

(a) $\mathrm{ZnSe}$

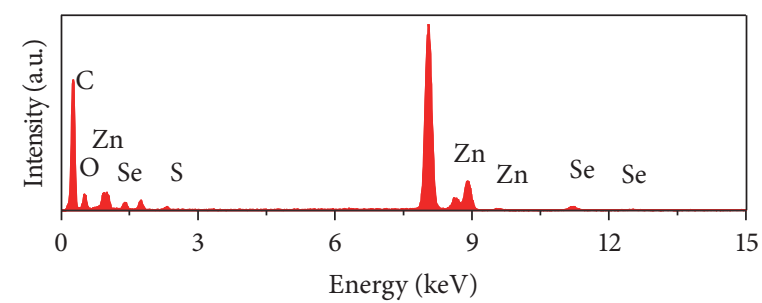

(b) $\mathrm{ZnSe} / \mathrm{ZnS}$

Figure 3: EDS spectra of ZnSe and ZnSe/ZnS-2-R-benzothiazole NCs: (a) ZnSe NCs; (b) ZnSe/ZnS-2-R-benzothiazole NCs.

thioglycerol, thioglycolic acid, and 3-mercaptopropionic acid usually is negligible and mainly shows a broad emission in the range of 400-600 nm. Alternatively, ligand Pen was used in the synthesis of aqueous $\mathrm{ZnSe}$ and $\mathrm{ZnSe} / \mathrm{ZnS} \mathrm{NCs}$, because Pen molecule structure contains $-\mathrm{SH},-\mathrm{NH}_{2}$, and $-\mathrm{COOH}$ group, which is similar to that of glutathione. With the introduction of $\mathrm{Zn}(\mathrm{OAc})_{2}$, capping reagent Pen, and sulfur source thiourea into the as-prepared $\mathrm{ZnSe}$ NCs reaction solution, the $\mathrm{ZnS}$ shell formed gradually and deposited around the $\mathrm{ZnSe}$ core to form the $\mathrm{ZnSe} / \mathrm{ZnS}$ core/shell nanostructures.

Figure 5 shows the temporal evolution of the UVvis absorption and PL emission spectra of the $\mathrm{ZnSe} / \mathrm{ZnS}$ core/shell NCs together with the initial ZnSe core NCs. All of the samples showed a sharp well-resolved first excitonic absorption onset from 300 to $450 \mathrm{~nm}$, which should be attributed to the electronic transition of $1 \mathrm{~S}(\mathrm{e})-1 \mathrm{~S}_{3 / 2}(\mathrm{~h})$. The absorption onsets of the $\mathrm{ZnSe} / \mathrm{ZnS}$ did not obviously shift to longer wavelength compared to that of the initial $\mathrm{ZnSe}$ core NCs, while the absorptivity of the $\mathrm{ZnSe} / \mathrm{ZnS}$ increased when the heating time was increased from 0 to $9 \mathrm{~h}$, which demonstrated the growth of the $\mathrm{ZnS}$ shell around $\mathrm{ZnSe}$ cores. However, at longer reaction time from 20 to $50 \mathrm{~h}$, the absorptivity of the NCs decreased perhaps due to that the concentration of the NC solution decreased originating from the aggregation of a few NCs. As shown in Figure 5(b), after heating for $1,9,20,25,35$, and $40 \mathrm{~h}$, the PL intensity of the NCs first increased gradually and then decreased. The PL peak position could approach to $437 \mathrm{~nm}$ in a period of $35 \mathrm{~h}$ growing time from the original $427 \mathrm{~nm}$ corresponding to the $\mathrm{ZnSe}$ core NCs. Figure 5(b) showed that the band-edge emission of the $\mathrm{ZnSe} / \mathrm{ZnS}$ NCs improved 36-fold and reached to the maxima after $35 \mathrm{~h}$ refluxing at $100^{\circ} \mathrm{C}$. The luminescence QYs were measured by an absolute method using an integrating sphere and amounted to $40 \%$. The observed PL enhancement is caused by passivation of surface trap states due to dual protection of both the $\mathrm{ZnS}$ shell and Pen stabilizer reagents. It was noted that the $-\mathrm{NH}_{2}$ and $-\mathrm{SH}$ of the Pen molecules simultaneously binding to $\mathrm{Zn}^{2+}$ on the surface of the NCs could efficiently eliminate dangling bonds, resulting in high PL QY.

Figure 6 shows the fluorescence change of the $\mathrm{ZnSe} / \mathrm{ZnS}$ NCs in PBS solution upon interaction with different concentrations of 2-hydroxy-5-(2,5-dimethyl-thienyl)-phenylbenzothiazole (2-R-benzothiazole) for a fixed time interval of $5 \mathrm{~min}$. When $0.1 \mathrm{~mL}$ of 2-R-benzothiazole was added into $\mathrm{ZnSe} / \mathrm{ZnS}$ NCs solution, a new PL peak was appeared at $557 \mathrm{~nm}$ and the PL of NCs solution displayed a broad double peaks character. It was evident that the PL intensity of the system was increased along with adding of the volumes of 2-R-benzothiazole (QY 51\%) and arrived maximum (QY $75 \%$ ) up to additions of $0.8 \mathrm{~mL}$ of 2-R-benzothiazole. Further adding 2-R-benzothiazole to $1.0 \mathrm{~mL}$ (Figure 6(g)), the PL of the NCs was almost constant. The observed fluorescence band centered $451 \mathrm{~nm}$ was attributed to the recombination of the charge carriers within surface states and $557 \mathrm{~nm}$ was originated from 2-R-benzothiazole-Zn complex. It was noted that the PL wavelengths of $\mathrm{ZnSe} / \mathrm{ZnS}$-2-R-benzothiazole NCs covered from 375 to $650 \mathrm{~nm}$, which made NCs available as a white LED material. Scheme 1 gives the conjugation of $\mathrm{ZnSe} / \mathrm{ZnS} \mathrm{NCs}$ and 2-R-benzothiazole. As shown in Scheme 1, when 2-R-benzothiazole was added into $\mathrm{ZnSe} / \mathrm{ZnS}$ NCs solution, the $\mathrm{N}$ and $\mathrm{O}$ atoms of the 2-R-benzothiazole molecules could bind to excess $\mathrm{Zn}^{2+}$ ions on the surfaces of the NCs to form 2-R-benzothiazole-Zn complex. When the 2R-benzothiazole was added into $\mathrm{ZnSe} / \mathrm{ZnS}$ NCs solution, the energy from Zn-2R-benzothiazole complexes can be transferred to ZnSe/ZnS NCs in composite NCs, which usually trends to PL quenching of the QDs. However, there 


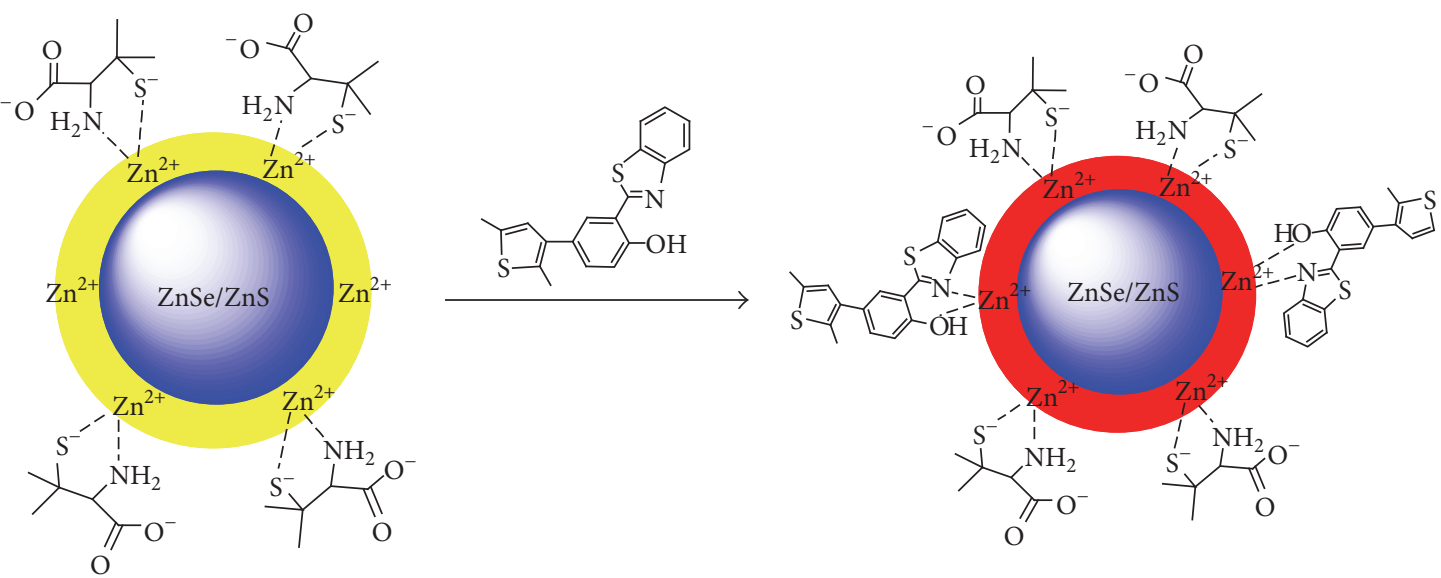

Scheme 1: The possible mechanism of the interaction of ZnSe/ZnS NCs with 2-R-benzothiazole.

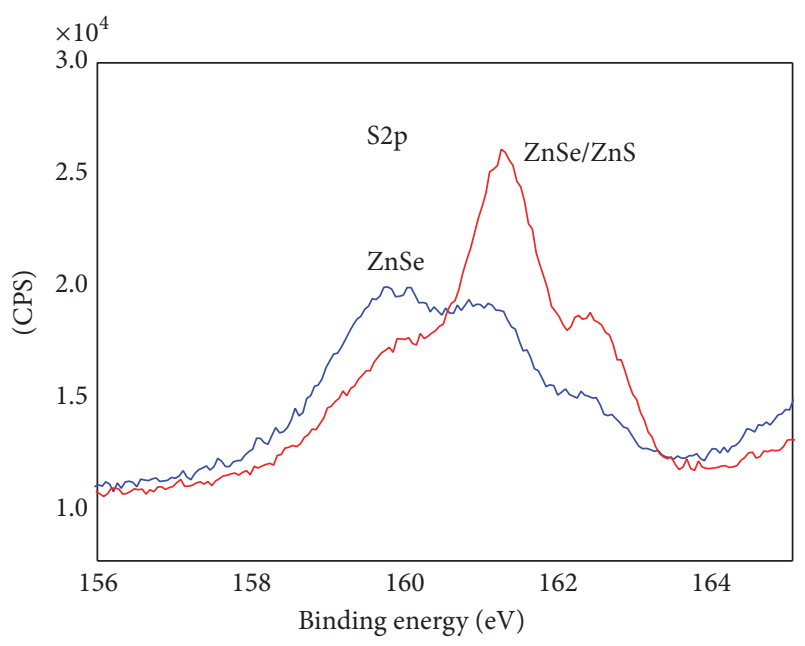

(a)

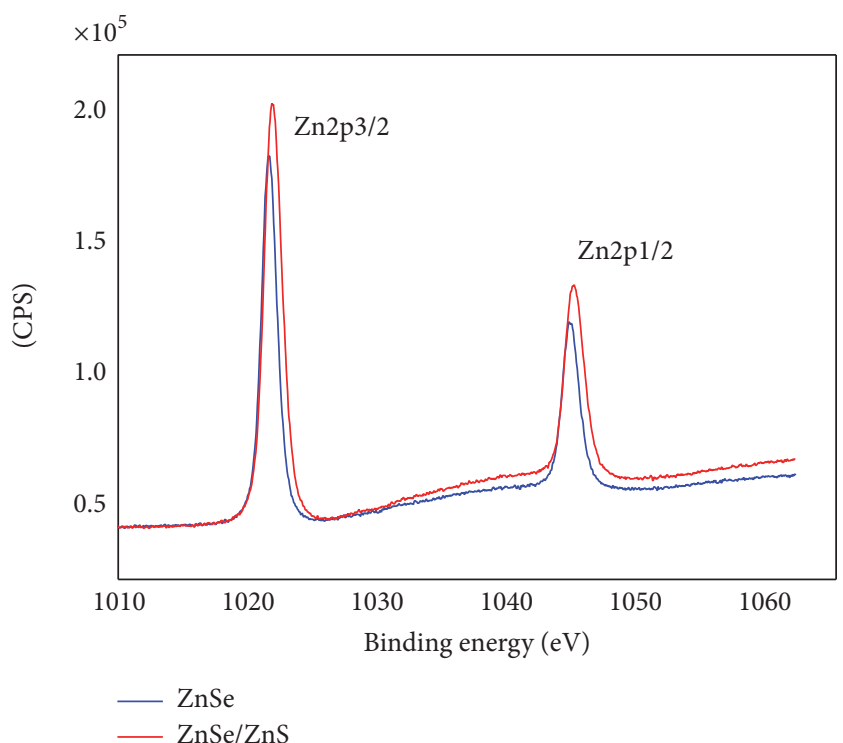

(c)

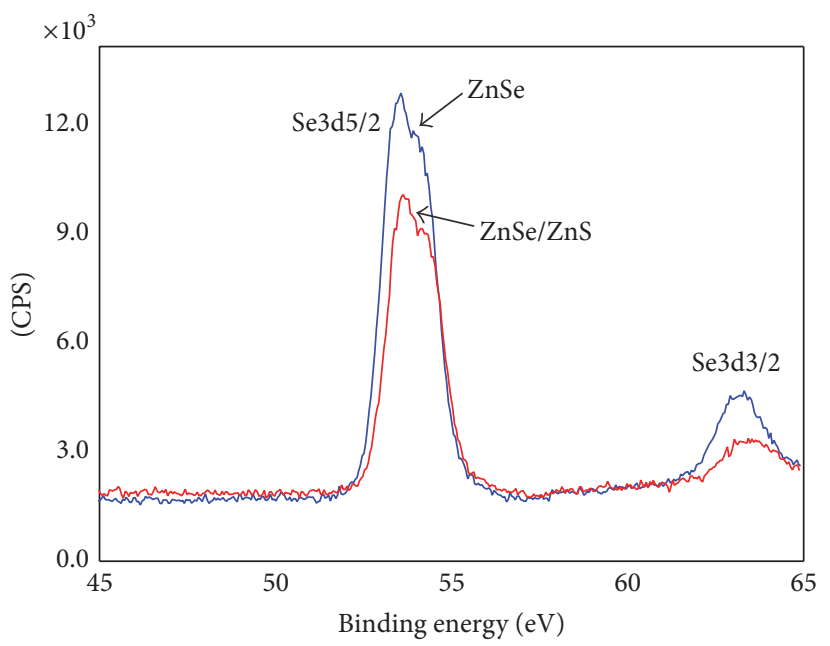

(b)

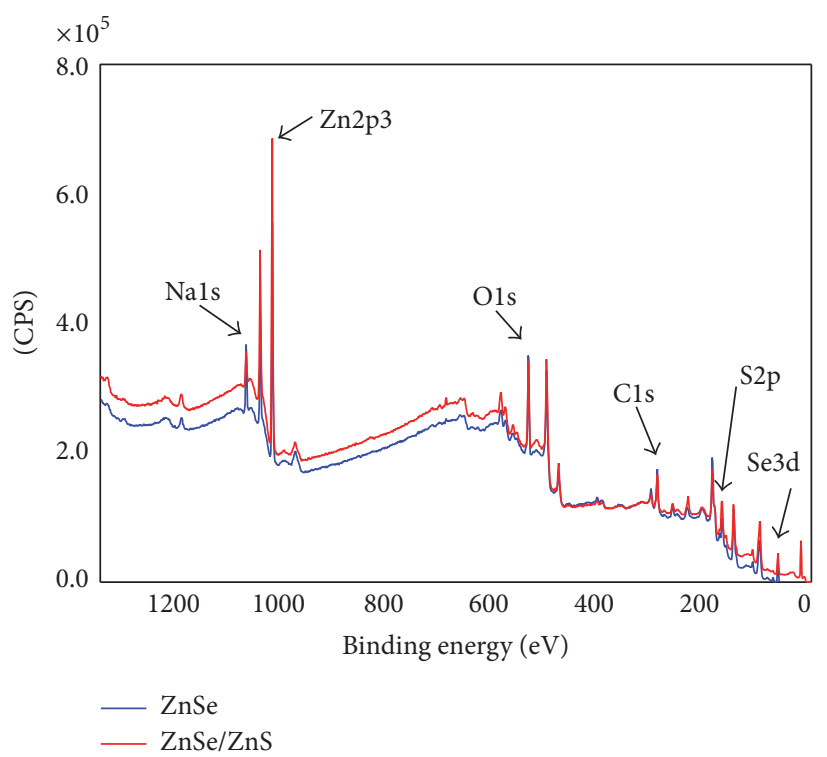

(d)

Figure 4: XPS spectra of ZnSe and ZnSe/ZnS-2-R-benzothiazole: (a) S 2p, (b) Se 3d levels of ZnSe and ZnSe/ZnS, (c) Zn 2p levels of $\mathrm{ZnSe} / \mathrm{ZnS}-2-\mathrm{R}-$ benzothiazole, and (d) total XPS spectra of ZnSe/ZnS-2-R-benzothiazole (top) and ZnSe (bottom) NCs. The ratios of S/Zn and Se/Zn of ZnSe and ZnSe/ZnS-2-R-benzothiazole are from 0.79 and 0.55 to 0.91 and 0.32 . 


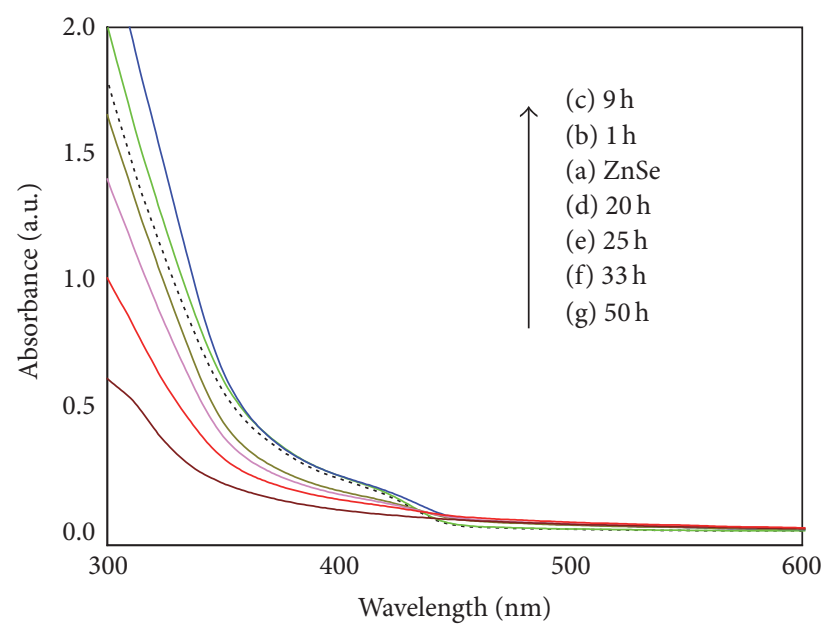

(a)

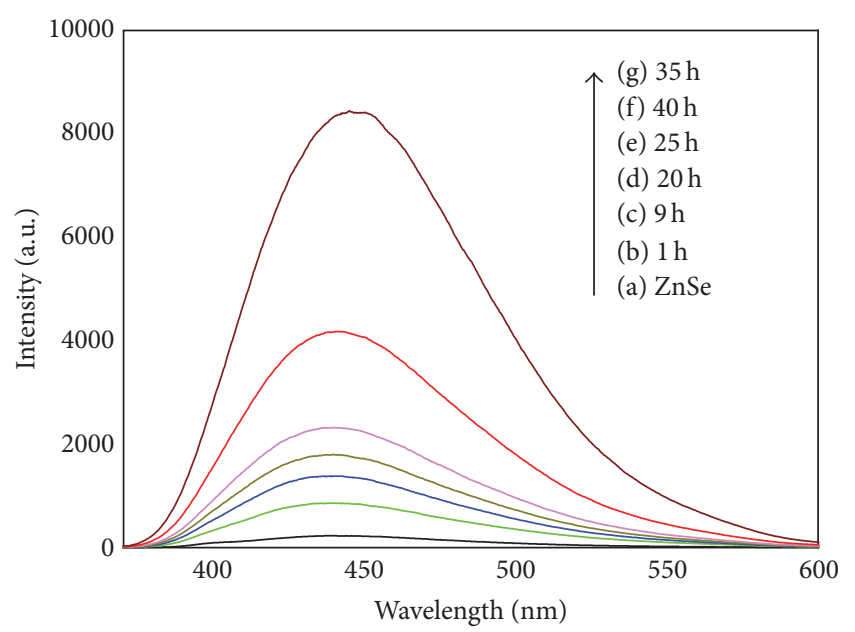

(b)

Figure 5: Typical temporal evolution of the absorption (a) and corresponding emission (b) spectra of ZnSe and ZnSe/ZnS NCs. Curve a represents the absorption (a) and corresponding emission (b) spectra of ZnSe NCs. Curves b g represent the absorption (a) and corresponding emission (b) spectra of ZnSe/ZnS NCs obtained for heating for 1, 9, 20, 25, 35, and $40 \mathrm{~h}$, respectively; the excitation wavelength was $360 \mathrm{~nm}$.

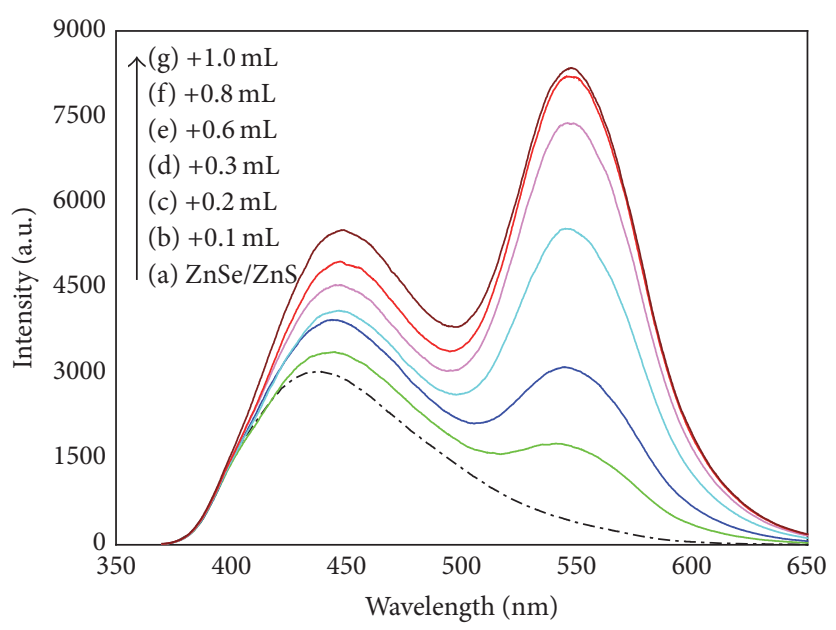

FIGURE 6: The fluorescence change of ZnSe/ZnS-2-R-benzothiazole NCs in the presence of variable volumes of 2-hydroxy-5-(2,5-dimethylthienyl)-phenyl-benzothiazole (2R-benzothiazole): (a) 0, (b) $0.1 \mathrm{~mL}$, (c) $0.2 \mathrm{~mL}$, (d) $0.3 \mathrm{~mL}$, (e) $0.6 \mathrm{~mL}$, (f) $0.8 \mathrm{~mL}$, and (g) $1.0 \mathrm{~mL}$ for a fixed time interval of $5 \mathrm{~min}$. All measurements were performed in a $50 \mathrm{mmol} / \mathrm{L} \mathrm{PBS}$ buffer solution $(\mathrm{pH}=7.4)$. The concentrations of $\mathrm{ZnSe} / \mathrm{ZnS}$ NCs and 2-R-benzothiazole were $1 \times 10^{-6} \mathrm{~mol} \mathrm{~L}^{-1}$ and $5 \times 10^{-5} \mathrm{~mol} \mathrm{~L}^{-1}$, respectively. The excitation wavelength was $360 \mathrm{~nm}$.

is no evidence of PL quenching of QDs in our system, which may be due to the complex formation resulting in two emission peaks and one of the peaks is overlapped with that of the $\mathrm{ZnSe} / \mathrm{ZnS} \mathrm{NCs}$.

To further prove the possible mechanism of the interaction of $\mathrm{ZnSe} / \mathrm{ZnS} \mathrm{NCs}$ with 2-R-benzothiazole, $0.2 \mathrm{~mL}$ of the ethylene glycol solution of 2-R-benzothiazole $(5 \times$ $\left.10^{-5} \mathrm{~mol} \cdot \mathrm{L}^{-1}\right)$ was added into $2 \mathrm{~mL}$ of the aqueous solution of $\mathrm{Zn}^{2+}\left(5 \times 10^{-6} \mathrm{~mol} \cdot \mathrm{L}^{-1}\right)$, resulting in the formation of 2R-benzothiazole-Zn complex. Figure 7(a) gives the absorption spectra of 2-R-benzothiazole with maximum peak at $355 \mathrm{~nm}$. Figure 7(b) shows PL emission spectra of the 2R-benzothiazole and 2-R-benzothiazole-Zn complex. It was evident that the PL peak of the 2-R-benzothiazole was at
$561 \mathrm{~nm}$ and split into two peaks at 450 and $548 \mathrm{~nm}$ after solvent of the 2-R-benzothiazole changed from the ethylene glycol solution to the mixture of ethylene glycol and water solution, and further 2-R-benzothiazole-Zn complex formed, which was agreed with the interaction of 2-R-benzothiazole with $\mathrm{ZnSe} / \mathrm{ZnS}$ NCs.

The ZnSe/ZnS-2-R-benzothiazole NCs were further studied by time-correlated single-photon counting (TCSPC) experiments. The decay profiles were recorded at the emission maxima of the NCs, at 451 and $557 \mathrm{~nm}$, upon excitation at $360 \mathrm{~nm}$, respectively, as presented in Figure 8. These PL decay curves at peak of $\mathrm{Em}=450 \mathrm{~nm}$ and $\mathrm{Em}=557(\lambda \mathrm{ex}=$ $360 \mathrm{~nm}$ ) can be well fitted by a biexponential equation $I(t)=$ $A_{1} \exp \left(-t / \tau_{1}\right)+A_{2} \exp \left(-t / \tau_{2}\right)[34-36]$. The observed lifetimes 


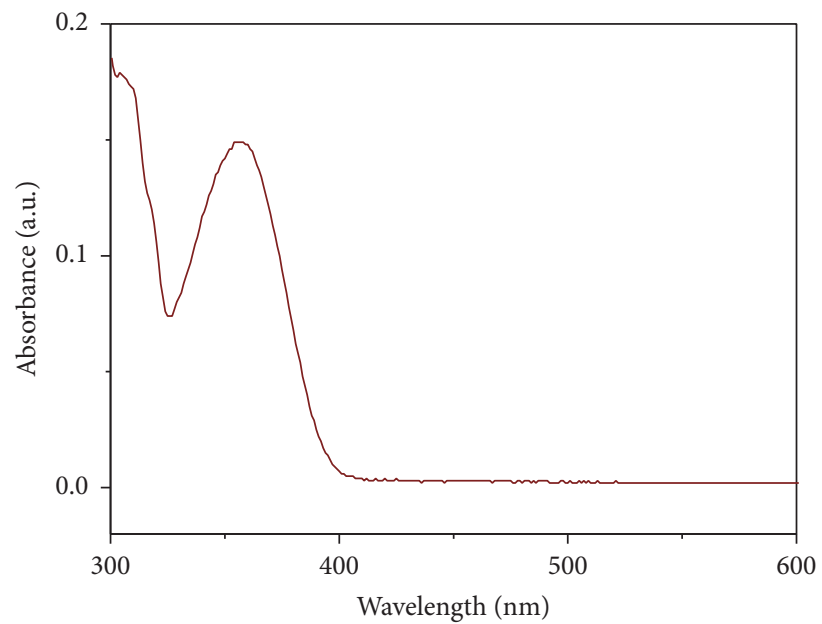

(a)

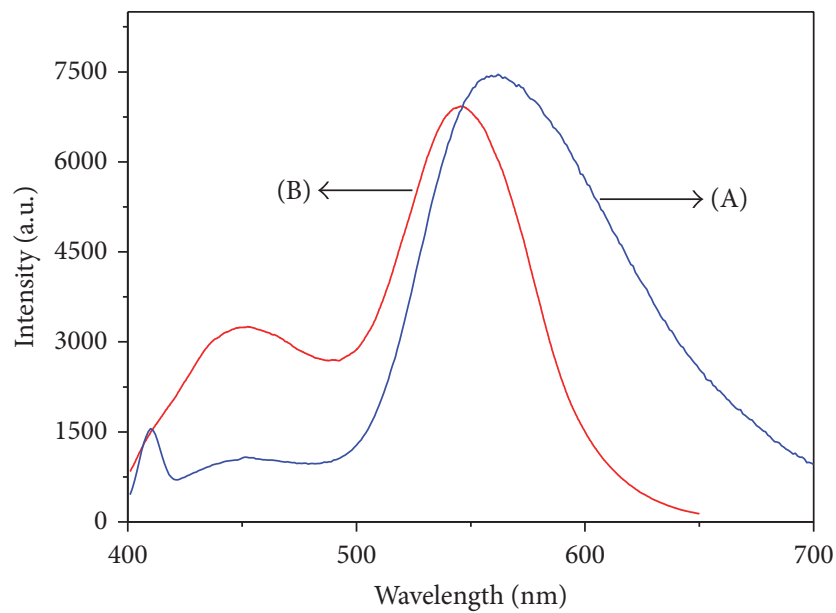

(b)

FIgURE 7: The absorption (a) of 2-R-benzothiazole and PL emission spectra (b) of 2-R-benzothiazole (A) and 2-R-benzothiazole-Zn complex (B). The concentrations of the $2 \mathrm{R}$-benzothiazole and the 2 -R-benzothiazole- $\mathrm{Zn}$ complex were $1 \times 10^{-5} \mathrm{~mol} \cdot \mathrm{L}^{-1}$.

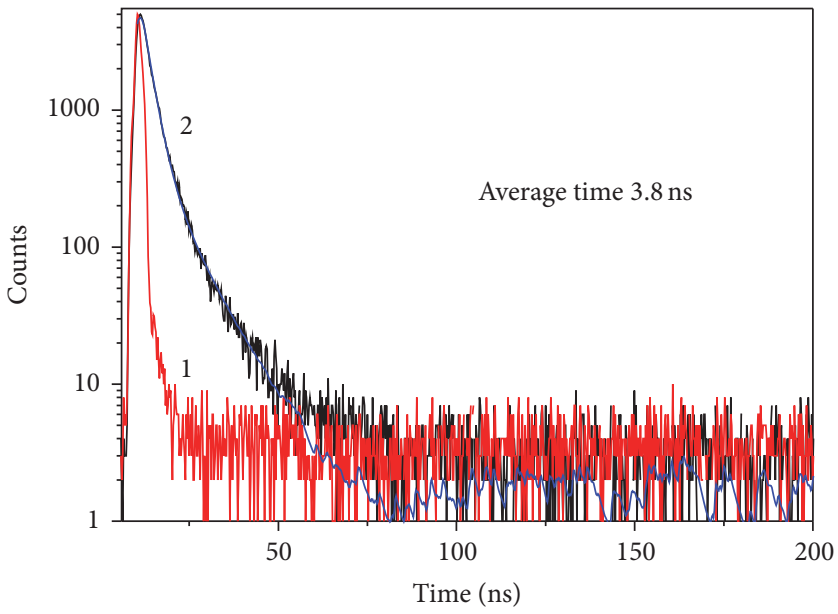

2. Em $451 \mathrm{~nm}$
1. LUDOX

(a)

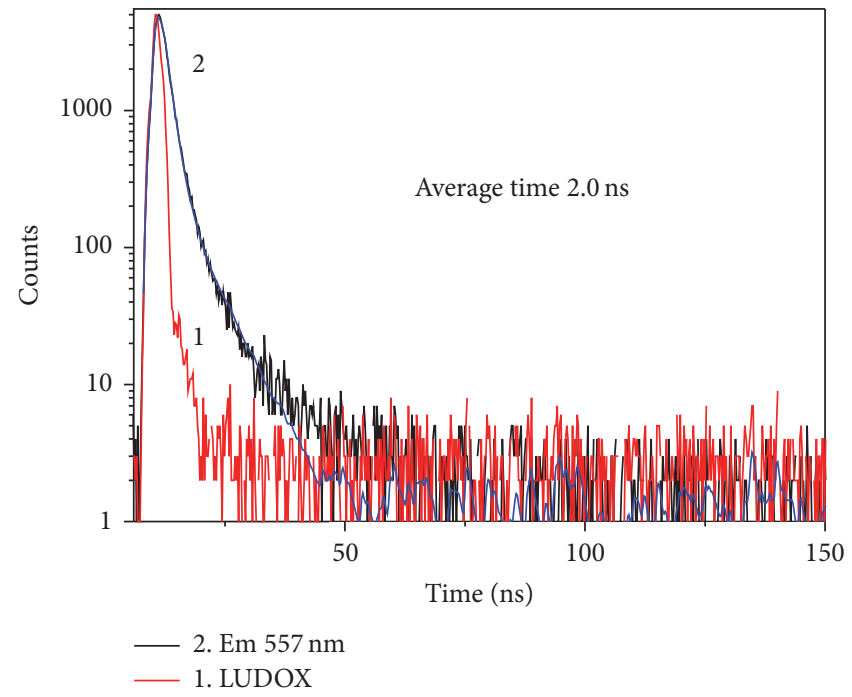

(b)

Figure 8: PL decay spectra of the ZnSe/ZnS-2-R-benzothiazole NCs at the emission maxima of the conjugation system, at $451 \mathrm{~nm}$ (a) and $557 \mathrm{~nm}$ (b), upon excitation at $360 \mathrm{~nm}$, respectively.

were $\tau_{1}=2.42 \mathrm{~ns}(\operatorname{Rel}: 78.2 \%), \tau_{2}=8.63 \mathrm{~ns}$ (Rel: $\left.21.8 \%\right)$, and $\chi^{2}=1.27$ for $450 \mathrm{~nm}$ peak, whereas $\tau_{1}=1.37 \mathrm{~ns}$ (Rel: $\left.85.2 \%\right)$, $\tau_{2}=5.83$ ns (Rel: $14.8 \%$ ), and $\chi^{2}=1.06$ for $557 \mathrm{~nm}$ peak. The average lifetimes of both peaks were $3.80 \mathrm{~ns}$ and $2.00 \mathrm{~ns}$, respectively. Obviously, the average emission lifetime of the latter was shorter than that of the former. The former was mainly attributed to the electron-hole pair recombination emission process of $\mathrm{ZnSe} / \mathrm{ZnS}$ NCs, whereas the latter was due to the bipolar charge (electron and hole) transport of 2R-benzothiazole-Zn complex.

Figure 9 shows the Commission Internationale de I'Eclairage (CIE) color coordinates of the ZnSe/ZnS NCs, dye (2-R-benzothiazole), and ZnSe/ZnS-dye hybrid NCs. As shown from Figure 9, ZnSe/ZnSNCs emit blue light with CIE coordinates of $(0.19,0.20)$, dye is 2-R-benzothiazole, which emits orange-red light with coordinates of $(0.41,0.47)$, and $\mathrm{ZnSe} / \mathrm{ZnS}$-dye is of a hybrid of dye and $\mathrm{ZnSe} / \mathrm{ZnS}$ NCs, which emits whit light with CIE coordinates of $(0.31,0.34)$.

To date, using ZnSe NCs with blue emitting as basis material, there were two methods of synthesizing of white LED material in the relevant literatures [32, 37]. One method was used by Mn-doping technique, and another was adopted by Se of $\mathrm{ZnSe} \mathrm{NCs}$ binding to Eu complex. Here, we presented the novel method of preparing of white LED material, which was obtained by $\mathrm{Zn}$ of $\mathrm{ZnSe} / \mathrm{ZnS} \mathrm{NCs}$ binding to dye. Particularly, the prepared NCs of ZnSe, ZnSe/ZnS, 


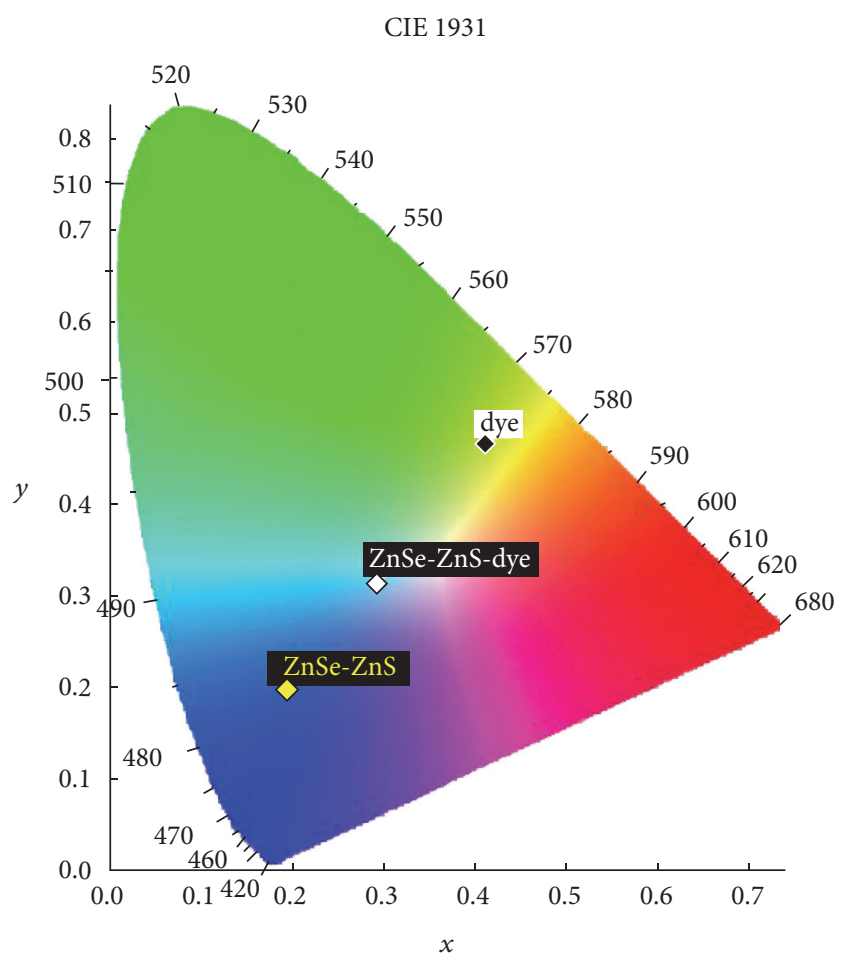

FIGURE 9: CIE color coordinates of the of ZnSe/ZnS NCs, dye (2-Rbenzothiazole), and $\mathrm{ZnSe} / \mathrm{ZnS}$-dye hybrid NCs. The corresponding CIE coordinates are $(0.18,0.19),(0.41,0.47)$, and $(0.31,0.34)$. The concentrations of $\mathrm{ZnSe} / \mathrm{ZnS} \mathrm{NCs}$ and dye were $1 \times 10^{-7} \mathrm{~mol} \mathrm{~L}^{-1}$ and $5 \times 10^{-5} \mathrm{~mol} \mathrm{~L}^{-1}$, respectively.

and $\mathrm{ZnSe} / \mathrm{ZnS} / 2 \mathrm{R}$-benzothiazole have all excellent colloidal and photostability over two months of study in ambient conditions.

\section{Conclusions}

Highly luminescent water-soluble NCs were synthesized by a facile and reproducible procedure in water. The penicillamine was used as a capping ligand and the formation of $\mathrm{ZnSe} / \mathrm{ZnS}$ NCs with $450 \mathrm{~nm}$ PL emission, which possesses a ZnS rich surface, was observed. This $\mathrm{ZnS}$ covering protects the NCs from nonradiative trapping and as a consequence, high QY were observed (40\%). Moreover, the PL QY of ZnSe/ZnS2-R-benzothiazole NCs improved greatly up to $75 \%$ and their wavelength covered from 375 to $650 \mathrm{~nm}$, making NCs available as a white LED material.

\section{Competing Interests}

The authors declare that they have no competing interests.

\section{Acknowledgments}

This work was financially supported by the Natural Science Foundation of China (nos. 21171150 and 21271159) and Henan Province Science and Technology Programs (no.
112102210002). The authors would like to acknowledge Dr. Xiao-Chun Li for experimental help.

\section{References}

[1] H. Peng, L. Zhang, T. H. M. Kjällman, C. Soeller, and J. TravasSejdic, "DNA hybridization detection with blue luminescent quantum dots and dye-labeled single-stranded DNA," Journal of the American Chemical Society, vol. 129, no. 11, pp. 3048-3049, 2007.

[2] M. Jiong, J.-Y. Cnen, Y. Zhang et al., "Photochemical instability of thiol-capped CdTe quantum dots in aqueous solution and living cells: process and mechanism," Journal of Physical Chemistry $B$, vol. 111, no. 41, pp. 12012-12016, 2007.

[3] Z. Deng, Y. Zhang, J. Yue, F. Tang, and Q. Wei, "Green and orange $\mathrm{CdTe}$ quantum dots as effective $\mathrm{pH}$-sensitive fluorescent probes for dual simultaneous and independent detection of viruses," The Journal of Physical Chemistry B, vol. 111, no. 41, pp. 12024-12031, 2007.

[4] X. Michalet, F. F. Pinaud, L. A. Bentolila et al., "Quantum dots for live cells, in vivo imaging, and diagnostics," Science, vol. 307, no. 5709, pp. 538-544, 2005.

[5] S. Kim, Y. T. Lim, E. G. Soltesz et al., "Near-infrared fluorescent type II quantum dots for sentinel lymph node mapping," Nature Biotechnology, vol. 22, no. 1, pp. 93-97, 2004.

[6] X. Gao, Y. Cui, R. M. Levenson, L. W. K. Chung, and S. Nie, "In vivo cancer targeting and imaging with semiconductor quantum dots," Nature Biotechnology, vol. 22, no. 8, pp. 969976, 2004.

[7] W.-H. Zhang, C.-X. Sui, X. Wang, G.-J. Yin, Y.-F. Liu, and D. Zhang, "Characterization of $\mathrm{Cr}(\mathrm{V})$-induced genotoxicity using CdTe nanocrystals as fluorescent probes," Analyst, vol. 139, no. 24, pp. 6357-6360, 2014.

[8] M. Bruchez Jr., M. Moronne, P. Gin, S. Weiss, and A. P. Alivisatos, "Semiconductor nanocrystals as fluorescent biological labels," Science, vol. 281, no. 5385, pp. 2013-2016, 1998.

[9] Y.-F. Liu, B. Xie, Z.-G. Yin, S.-M. Fang, and J.-B. Zhao, "Synthesis of highly stable $\mathrm{CdTe} / \mathrm{CdS}$ quantum dots with biocompatibility," European Journal of Inorganic Chemistry, no. 10, pp. 1501-1506, 2010.

[10] Y.-F. Liu and J.-S. Yu, "In situ synthesis of highly luminescent glutathione-capped CdTe/ZnS quantum dots with biocompatibility," Journal of Colloid and Interface Science, vol. 351, no. 1, pp. $1-9,2010$

[11] J. Han, H. Zhang, Y. Tang, Y. Li, X. Yao, and B. Yang, "Role of redox reaction and electrostatics In transition-metal impuritypromoted photoluminescence evolution of water-soluble $\mathrm{ZnSe}$ nanocrystals," Journal of Physical Chemistry C, vol. 113, no. 18, pp. 7503-7510, 2009.

[12] J. W. M. Chon, M. Gu, C. Bullen, and P. Mulvaney, “Threephoton excited band edge and trap emission of CdS semiconductor nanocrystals," Applied Physics Letters, vol. 84, no. 22, pp. 4472-4474, 2004.

[13] A. Shavel, N. Gaponik, and A. Eychmüller, "Efficient UVblue photoluminescing thiol-stabilized water-soluble alloyed $\mathrm{ZnSe}(\mathrm{S})$ nanocrystals," Journal of Physical Chemistry B, vol. 108, no. 19, pp. 5905-5908, 2004.

[14] M. A. Hines and P. Guyot-Sionnest, "Bright UV-blue luminescent colloidal ZnSe nanocrystals," Journal of Physical Chemistry $B$, vol. 102, no. 19, pp. 3655-3657, 1998. 
[15] D. J. Norris, N. Yao, F. T. Charnock, and T. A. Kennedy, "Highquality manganese-doped ZnSe nanocrystals," Nano Letters, vol. 1, no. 1, pp. 3-7, 2001.

[16] A. Nag, S. Chakraborty, and D. D. Sarma, "To dope $\mathrm{Mn}^{2+}$ in a semiconducting nanocrystal," Journal of the American Chemical Society, vol. 130, no. 32, pp. 10605-10611, 2008.

[17] J. Q. Zhuang, X. D. Zhang, G. Wang, D. M. Li, W. S. Yang, and T. J. Li, "Synthesis of water-soluble $\mathrm{ZnS}: \mathrm{Mn}^{2+}$ nanocrystals by using mercaptopropionic acid as stabilizer," Journal of Materials Chemistry, vol. 13, no. 7, pp. 1853-1857, 2003.

[18] R. Beaulac, P. I. Archer, J. Van Rijssel, A. Meijerink, and D. R. Gamelin, "Exciton storage by $\mathrm{Mn}^{2+}$ in colloidal $\mathrm{Mn}^{2+}$-Doped CdSe quantum dots," Nano Letters, vol. 8, no. 9, pp. 2949-2953, 2008.

[19] N. Pradhan, D. M. Battaglia, Y. C. Liu, and X. G. Peng, "Efficient, stable, small, and water-soluble doped ZnSe nanocrystal emitters as non-cadmium biomedical labels," Nano Letters, vol. 7, no. 2, pp. 312-317, 2007.

[20] H. Althues, R. Palkovits, A. Rumplecker et al., "Synthesis and characterization of transparent luminescent $\mathrm{ZnS}: \mathrm{Mn} / \mathrm{PMMA}$ nanocomposites," Chemistry of Materials, vol. 18, no. 4, pp. 1068-1072, 2006.

[21] A. Aboulaich, L. Balan, J. Ghanbaja, G. Medjahdi, C. Merlin, and R. Schneider, "Aqueous route to biocompatible $\mathrm{ZnSe}: \mathrm{Mn} / \mathrm{ZnO}$ core/shell quantum dots using 1-thioglycerol as stabilizer," Chemistry of Materials, vol. 23, no. 16, pp. 3706-3713, 2011.

[22] N. Gaponik, D. V. Talapin, A. L. Rogach et al., "Thiol-capping of CDTe nanocrystals: an alternative to organometallic synthetic routes," Journal of Physical Chemistry B, vol. 106, no. 29, pp. 7177-7185, 2002.

[23] H. Y. Acar, R. Kas, E. Yurtsever, C. Ozen, and I. Lieberwirth, "Emergence of 2MPA as an effective coating for highly stable and luminescent quantum dots," Journal of Physical Chemistry C, vol. 113, no. 23, pp. 10005-10012, 2009.

[24] Z. Deng, F. L. Lie, S. Shen, I. Ghosh, M. Mansuripur, and A. J. Muscat, "Water-based route to ligand-selective synthesis of $\mathrm{ZnSe}$ and $\mathrm{Cd}$-doped $\mathrm{ZnSe}$ quantum dots with tunable ultraviolet A to blue photoluminescence," Langmuir, vol. 25, no. 1, pp. 434-442, 2009.

[25] S. Xiong, S. Huang, A. Tang, and F. Teng, "Synthesis and luminescence properties of water-dispersible ZnSe nanocrystals," Materials Letters, vol. 61, no. 29, pp. 5091-5094, 2007.

[26] G.-Y. Lan, Y.-W. Lin, Y.-F. Huang, and H.-T. Chang, "Photoassisted synthesis of highly fluorescent $\mathrm{ZnSe}(\mathrm{S})$ quantum dots in aqueous solution," Journal of Materials Chemistry, vol. 17, no. 25, pp. 2661-2666, 2007.

[27] C. Wang, X. Gao, Q. Ma, and X. Su, "Aqueous synthesis of mercaptopropionic acid capped $\mathrm{Mn}^{2+}$-doped $\mathrm{ZnSe}$ quantum dots," Journal of Materials Chemistry, vol. 19, no. 38, pp. 70167022, 2009.

[28] Z. Fang, P. Wu, X. Zhong, and Y.-J. Yang, "Synthesis of highly luminescent $\mathrm{Mn}$ : ZnSe/ZnS nanocrystals in aqueous media," Nanotechnology, vol. 21, no. 30, Article ID 305604, 2010.

[29] Y.-F. Liu, G.-Q. Wang, J.-B. Zhao, L. Jiang, S.-M. Fang, and Y.-A. Sun, "Synthesis of chiral silver nanoclusters capped with small molecules," Colloids and Surfaces A: Physicochemical and Engineering Aspects, vol. 426, pp. 12-17, 2013.

[30] Y.-F. Liu, L. Wang, W.-Z. Shi, Y.-H. Zhang, and S.-M. Fang, "Synthesis and characterization of chiral $\mathrm{Ag}_{2} \mathrm{~S}$ and $\mathrm{Ag}_{2} \mathrm{~S}-\mathrm{Zn}$ nanocrystals," RSC Advances, vol. 4, no. 95, pp. 53142-53148, 2014.
[31] Z. Fang, Y. Li, H. Zhang, X. Zhong, and L. Zhu, "Facile synthesis of highly luminescent UV-blue-emitting ZnSe/ZnS Core/Shell nanocrystals in aqueous media," Journal of Physical Chemistry C, vol. 113, no. 32, pp. 14145-14150, 2009.

[32] C. L. Wang, S. H. Xu, Y. B. Wang, Z. Y. Wang, and Yi. P. Cui, "Aqueous synthesis of multilayer $\mathrm{Mn}: \mathrm{ZnSe} / \mathrm{Cu}: \mathrm{ZnS}$ quantum dots with white light emission," Journal of Materials Chemistry C, vol. 2, no. 4, pp. 660-666, 2014.

[33] Y. Zheng, Z. Yang, and J. Y. Ying, "Aqueous synthesis of glutathione-capped $\mathrm{ZnSe}$ and $\mathrm{Zn}_{1-\mathrm{x}} \mathrm{Cd}_{\mathrm{x}}$ Se alloyed quantum dots," Advanced Materials, vol. 19, no. 11, pp. 1475-1479, 2007.

[34] D.-E. Nam, W.-S. Song, and H. Yang, "Facile, air-insensitive solvothermal synthesis of emission-tunable $\mathrm{CuInS}_{2} / \mathrm{ZnS}$ quantum dots with high quantum yields," Journal of Materials Chemistry, vol. 21, no. 45, pp. 18220-18226, 2011.

[35] X. Y. Wang, L. H. Qu, J. Y. Zhang, X. G. Peng, and M. Xiao, "Surface-related emission in highly luminescent CdSe quantum dots," Nano Letters, vol. 3, no. 8, pp. 1103-1106, 2003.

[36] A. L. Rogach, T. Franzl, T. A. Klar et al., "Aqueous synthesis of thiol-capped CdTe nanocrystals: state-of-the-art," The Journal of Physical Chemistry C, vol. 111, no. 40, pp. 14628-14637, 2007.

[37] B.-H. Kwon, H. S. Jang, H. S. Yoo et al., "White-light emitting surface-functionalized $\mathrm{ZnSe}$ quantum dots: europium complex-capped hybrid nanocrystal," Journal of Materials Chemistry, vol. 21, no. 34, pp. 12812-12818, 2011. 

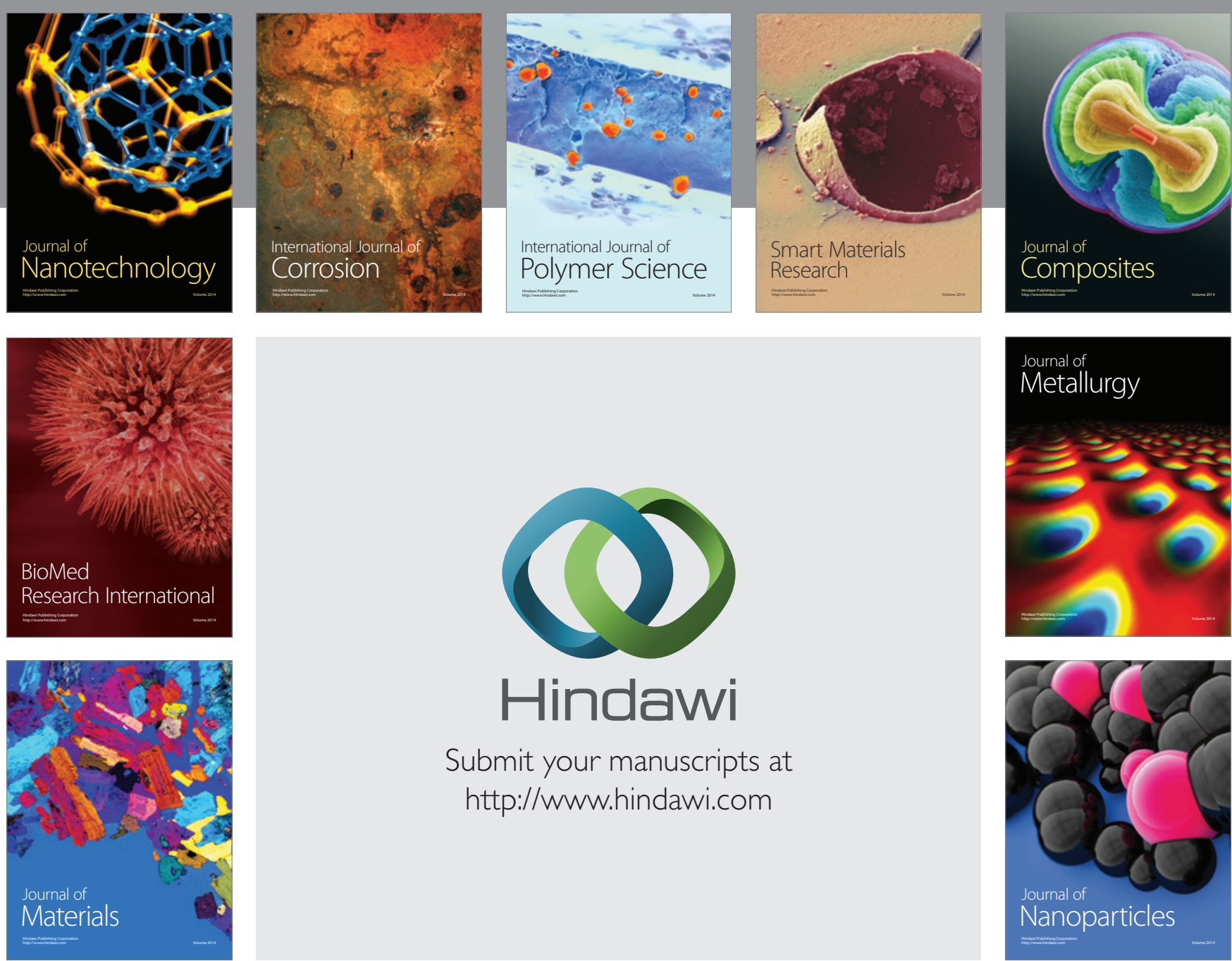

\section{Hindawi}

Submit your manuscripts at

http://www.hindawi.com

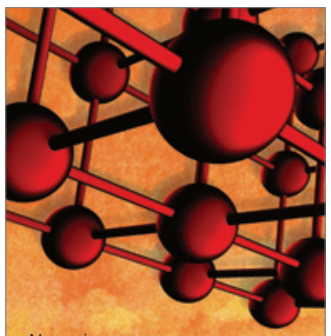

Materials Science and Engineering
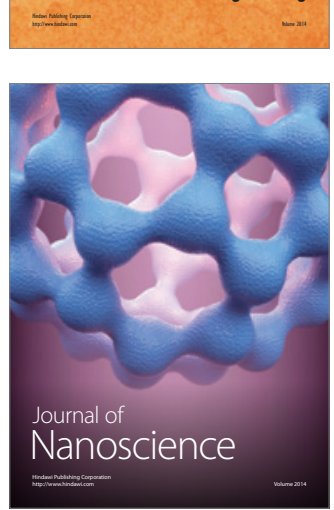
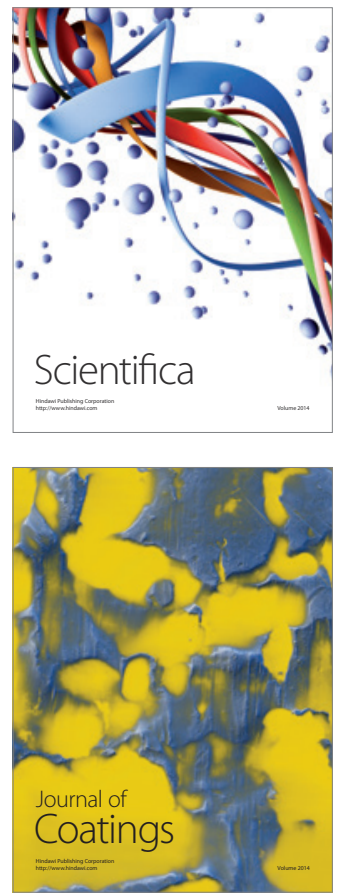
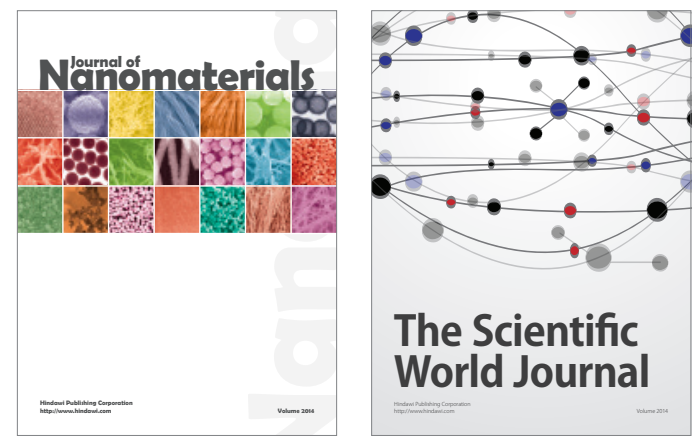

The Scientific World Journal
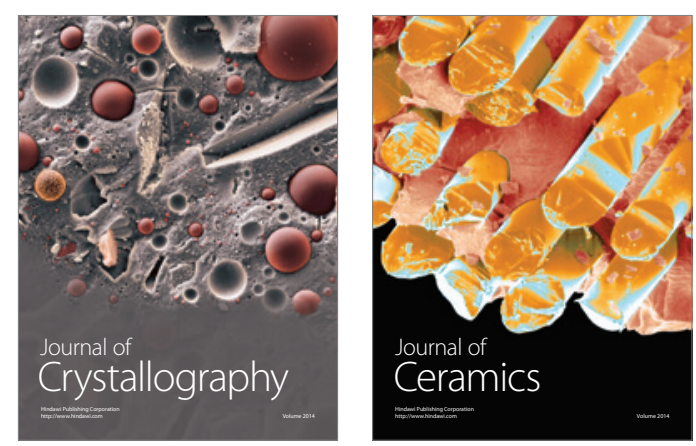
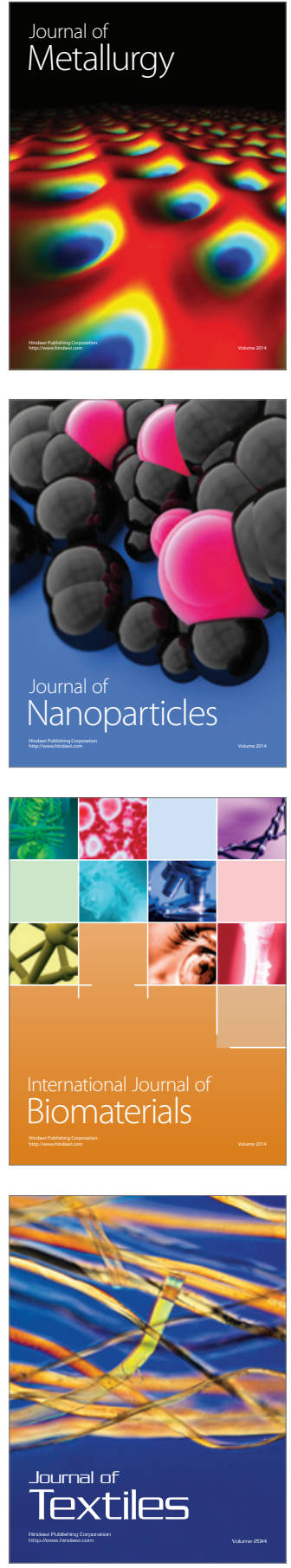